\title{
Implementasi Metode Image Tracking Vuforia Pada Pengenalan Hewan Menggunakan Augmented Reality Berbasis Android
}

\author{
Dwita Deslianti 1, Sumarsih 2 \\ 1,2Teknik Informatika Fakultas Teknik Universitas Muhammadiyah Bengkulu \\ 1,2J1 Bali Po Box 118 Kota Bengkulu 38119 Telp. 0736-22765 \\ Idwitadeslianti@umb.ac.id,2sumarsih@gmail.com
}

\begin{abstract}
Abstrak - Gambar atau foto hewan yang terlalu kompleks menjadikannya kurang efektif untuk kegiatan pembelajaran. Dari masalah di atas penulis memberikan solusi dengan memanfaatkan teknologi saat ini yang berkembang pesat maka diambilah salah satu teknologi yang berkembang dalam hal visual 3D yaitu Augmented Reality. Dari hasil analisa, perancangan, pengujian dan implementasi program dapat disimpulkan aplikasi menangkap marker pada jarak < 25CM untuk menampilkan objek 3D dari marker tersebut dan Sudut kemiringan yang masih terjangkau oleh aplikasi yang dibuat ketika marker telah ditangkap kamera ialah $>15^{\circ}$, setelah melakukan percobaan rating bintang pada Database Marker minimal 4 bintang, Respon Objek 3D dalam mengenali marker pada sistem \pm 1 detik setelah kamera siap.
\end{abstract}

\section{Kata Kunci : Implementasi, Image Tracking Vuforia, Augmented Reality, Android}

Abstract - Images or photographs of animals that are too complex make it less effective for learning activities. From the problem above, the writer provides a solution by utilizing current technology that is developing rapidly, so one technology that is developed in terms of $3 \mathrm{D}$ visualization is Augmented Reality. From the analysis, design, testing and implementation of the program it can be concluded that the application captures the marker at a distance of $<25 \mathrm{CM}$ to display the $3 \mathrm{D}$ object of the marker and the angle of inclination that is still reachable by the application created when the marker has been captured by the camera is $>15$, after conduct star rating experiments on a Marker Database of at least 4 stars, 3D Object Response in recognizing markers on the system \pm 1 second after the camera is ready.

\section{Keyword : Implementation, Image Tracking Vuforia, Augmented Reality, Android}

\section{Pendahuluan}

Augmented Reality (AR) merupakan bidang ilmu teknologi yang menerapkan objek virtual 3D kedalam ruang lingkup nyata. Dalam perkembangannya teknologi AR ini mengizinkan user untuk dapat berinteraksi langsung atau secara realtime terhadap objek 3D [1] [2]. Perkembangan AR saat ini telah berkembang ke berbagai aspek seperti pengembangan pada buku cerita rakyat [3], bahkan dalam dunia pendidikan seperti media pembelajaran.

Pada perkembangannya AR selama ini masih menggunakan gambar marker (penanda), dimana gambar marker ini sendiri hanyalah bentuk kotak-kotak berwarna hitam dan berlatar belakang putih, dengan menggunakan penanda ini akan sangat sulit untuk menentukan penanda yang unik dan dianggap tepat agar tidak salah dalam pengenalan objek[4].

Pengembangan AR menggunakan penanda juga mempunyai kelemahan pada penggunaan ruang dan obyek yang dilacak menjadi tidak efisien [4], juga kurang menarik apabila diimpilementasikan kepada objek media pembelajaran dan akan lebih menarik apabila menggunakan objek gambar yang nyata.
Pada pengujian yang telah dilakukan juga membuktikan bahwa semakin kompleks penanda yang digunakan maka akan semakin baik pengenalan objek 3D yang akan ditampilkan, maupun dilihat dari setiap sudut kemiringan kamera yang akan mendeteksi penanda yang digunakan [5].

Pada media pembelajaran yang kerap kali digunakan oleh para tenaga pengajar sekolah di indonesia, penulis meneliti gambar yang digunakan cukup kompleks dan dapat digunakan untuk penanda pengenalan objek $3 \mathrm{D}$, dan juga dapat mempermudah bagi tenaga pengajar dalam menyampaikan meteri serta dapat memanfaatkan perekembangan teknologi saat ini [6].

\section{Metode Penelitian}

\subsection{Tahapan Penelitian}

Penelitian pengembangan teknologi Augmented Reality (AR) ini menggunakan platform Android dan menggunakan platform vuforia sebagai alat bantu dalam pengenalan penanda yang digunakan.

Metodologi yang digaunakan dalam pengembangan sistem ini menggunakan metode pengembangan aplikasi Multimedia Life Cycle 
(MDLC). Dimana pada metodologi ini menggunakan 6 tahapan yaitu: concept, design, material collecting, assembly, testing dan distribution [7].

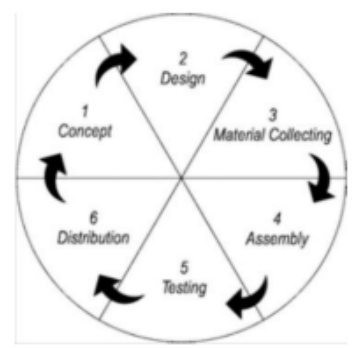

Gambar 1. Multimendia Life Cycle (MDLC)

a) Concept

Menentukan objek penanda yang akan digunakan yang merupakan tahapan pengumpulan data pada penelitian ini.

Data yang digunakan merupakan gambar objek yang digunakan pada bahan pembelajaran sesuai dengan pembahasan tematik yang telah ditentukan oleh kurikulum K-13 Dinas Pendidikan.

b) Design

Pada tahapan ini meruapakan tahap pembuatan alur kerja sistem serta tampilan struktu menu dan design aplikasi yang akan dikembangkan.

Seperti gambar dibawah ini adalah flowchart pengembangan aplikasi yang digunakan.

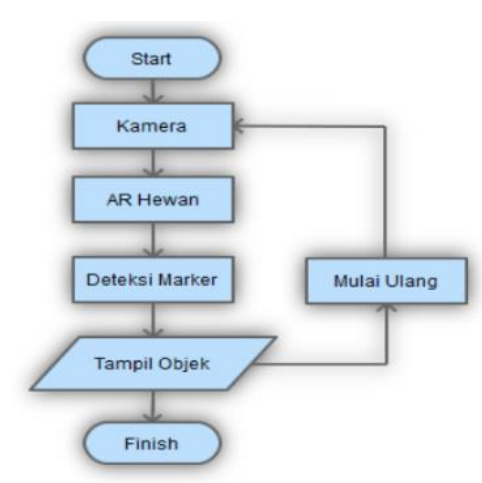

Gambar 2. Flowchar Pengembangan Aplikasi

Selanjutnya yaitu tahapan penentuan struktur menu pada aplikasi yang akan dikembangkan, seperti yang tampak pada gambar dibawah ini:

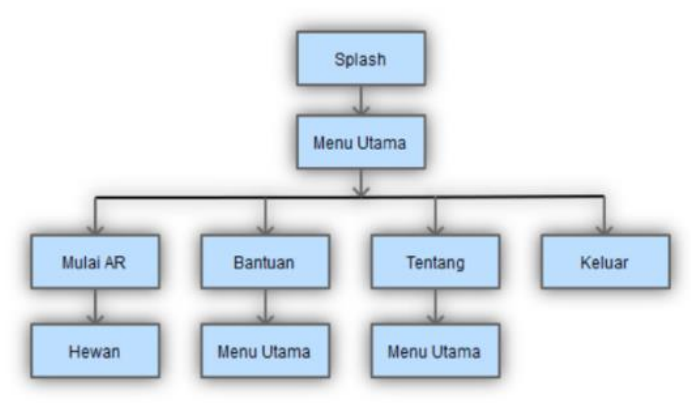

Gambar 3. Struktur menu aplikasi

Design rancangan sesuai dengan struktur menu yang telah dirancang sesuai dengan gambar diatas, terdiri dari Splash Screen, Mulai AR, Bantuan, Tentang, Keluar, serta pengenalan penanda terdapat pada pilihan Hewan. Dimana tampilan design dapat dilihat pada gambar-gambar dibawah ini:

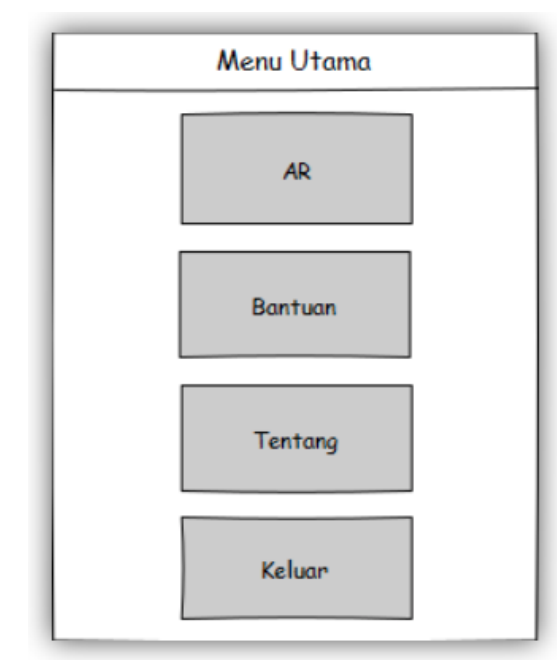

Gambar 4. Menu Utama

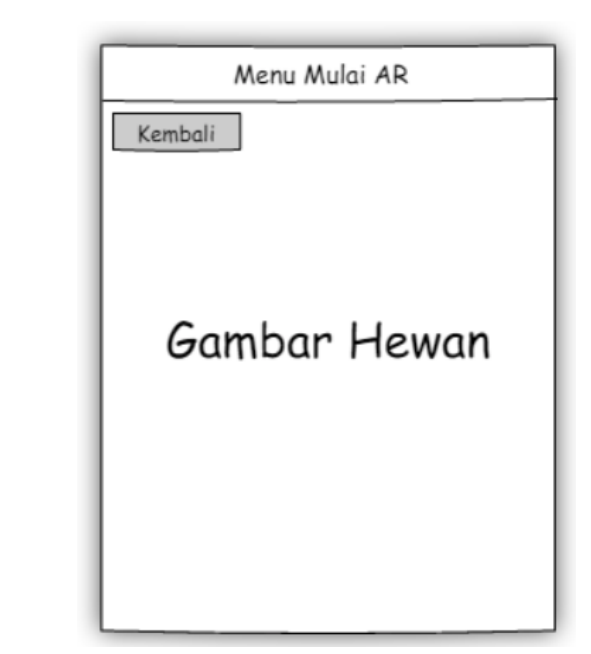

Gambar 5. Proses Scan AR 
c) Material Collection

Proses pengumpulan data yang digunakan yaitu data akan diambil pada objek penelitian yaitu SD N 10 Kabupaten Mukomuko Provinsi Bengkulu.

d) Asembly

Tahapan pembuatan aplikasi yang akan dibuat sesuai dengan struktu yang telah diajukan. Dimana pada proses ini akan menggabungkan materi-materi serta seluruh data yang telah dikumpulkan.

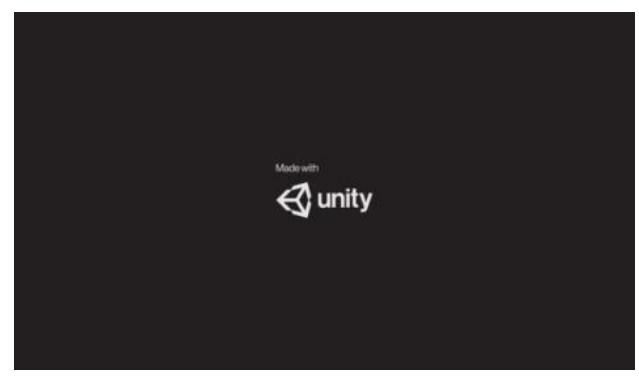

Gambar 6. Tampilan Awal

Gambar diatas merupakan contoh gambar tahapan awal tools yang digunakan yaitu menggunakan unity yang nantinya akan disinkronikasikan menggunakan vuforia untuk pengenalan penanda yang akan digunakan.

e) Testing dan Distribution

Tahapan dimana pada penelitian akan menguji coba aplikasi yang dikembangkan sesuai dengan alur penelitian yang diusulkan.

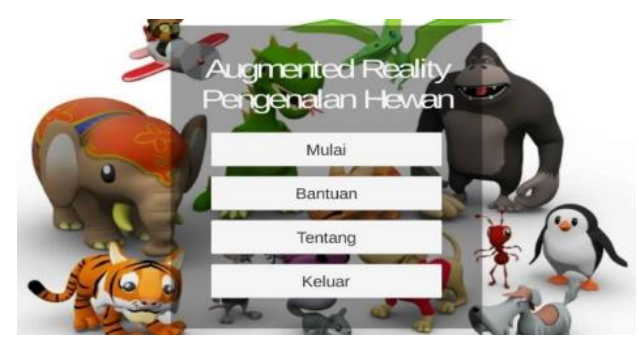

Gambar 7. Tampilan Menu Awal

Gambar diatas adalah tampilan menu awal aplikasi yang telah dikembangkan. Tampak pada tampilan menu awal terdapat beberapa pilihan yang disajikan sesuai dengan design yang digunakan.

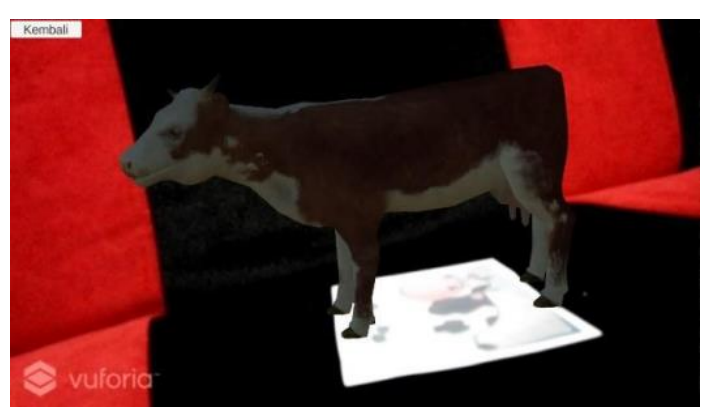

Gambar 8. Tampilan Scan AR

Gambar diatas merupakan gambar tampilan pada saat scan awal penanda dimana penanda menggunakan gambar yang menarik, sesuai dengan data gambar yang diambil dari objek penelitian.

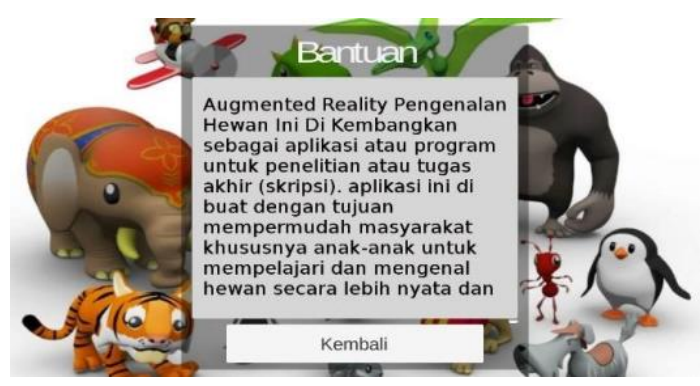

Gambar 9. Tampilan Menu Bantuan

Gambar diatas adalah tampilan bantuan bagi pengguna agar memudahkan pengguna untuk menjalankan aplikasi yang dikembangkan.

\section{Hasil dan Pembahasan}

Hasil pada penelitian ini didapatkan berdasarkan hasil testing dan distribusi sesuai dengan tahapan metodologi MDLC. Tahapan testing nantinya akan di ujicoba dan akan dicatat dalam bentuk tabel hasil pengujian seperti diabawah ini:

Tabel 1. Pengujian Menu Mulai AR

\begin{tabular}{|l|l|l|l|}
\hline \multicolumn{4}{|c|}{ Kasus Hasil Uji (Data Benar) } \\
\begin{tabular}{|} 
Data \\
Masukan
\end{tabular} & $\begin{array}{c}\text { Yang } \\
\text { Diharapkan }\end{array}$ & Pengamatan & $\begin{array}{c}\text { Kesimpu } \\
\text { lan }\end{array}$ \\
\hline $\begin{array}{l}\text { Klik Menu } \\
\text { Mulai AR }\end{array}$ & Dapat & Menu Mulai & $(\sqrt{ })$ \\
& menampilkan & AR berhasil & $\begin{array}{l}\text { Diterima } \\
{[]}\end{array}$ \\
& Menu Mulai & tampil & Ditolak \\
\hline $\begin{array}{l}\text { Klik Tombol } \\
\text { kembali }\end{array}$ & Dapat & Berhasil & $(\sqrt{ })$ \\
& kembali dari & kembali dari & Diterima \\
& menu Mulai & Menu Mulai & {[]} \\
& AR & AR & Ditolak \\
\hline
\end{tabular}


Tabel 2. Pengujian Menu Bantuan

\begin{tabular}{|c|c|c|c|}
\hline \multicolumn{4}{|c|}{ Kasus Hasil Uji (Data Benar) } \\
\hline $\begin{array}{c}\text { Data } \\
\text { Masukan }\end{array}$ & $\begin{array}{c}\text { Yang } \\
\text { Diharapkan }\end{array}$ & Pengamatan & $\begin{array}{c}\text { Kesimpu } \\
\text { lan }\end{array}$ \\
\hline $\begin{array}{l}\text { Klik Menu } \\
\text { Bantuan }\end{array}$ & $\begin{array}{l}\text { Dapat } \\
\text { menampilkan } \\
\text { Menu } \\
\text { Bantuan }\end{array}$ & $\begin{array}{l}\text { Menu } \\
\text { Bantuan } \\
\text { berhasil } \\
\text { tampil }\end{array}$ & $\begin{array}{l}(\sqrt{ }) \\
\text { Diterima } \\
{[]} \\
\text { Ditolak }\end{array}$ \\
\hline $\begin{array}{l}\text { Klik Tombol } \\
\text { kembali }\end{array}$ & $\begin{array}{l}\text { Dapat } \\
\text { kembali dari } \\
\text { menu } \\
\text { Bantuan }\end{array}$ & $\begin{array}{l}\text { Berhasil } \\
\text { kembali dari } \\
\text { menu } \\
\text { Bantuan }\end{array}$ & $\begin{array}{l}(\sqrt{ }) \\
\text { Diterima } \\
{[]} \\
\text { Ditolak }\end{array}$ \\
\hline
\end{tabular}

Tabel 3 Pengujian Menu Tentang

\begin{tabular}{|c|c|c|c|}
\hline \multicolumn{4}{|c|}{ Kasus Hasil Uji (Data Benar) } \\
\hline $\begin{array}{c}\text { Data } \\
\text { Masukan }\end{array}$ & $\begin{array}{c}\text { Yang } \\
\text { Diharapkan }\end{array}$ & Pengamatan & Kesimpulan \\
\hline $\begin{array}{l}\text { Klik Menu } \\
\text { Tentang }\end{array}$ & $\begin{array}{l}\text { Dapat } \\
\text { menampilkan } \\
\text { Menu } \\
\text { Tentang }\end{array}$ & $\begin{array}{l}\text { Menu } \\
\text { Tentang } \\
\text { berhasil } \\
\text { tampil }\end{array}$ & $\begin{array}{l}\text { ( } \sqrt{ }) \text { Diterima } \\
\text { [ ] Ditolak }\end{array}$ \\
\hline $\begin{array}{l}\text { Klik Tombol } \\
\text { kembali }\end{array}$ & $\begin{array}{l}\text { Dapat } \\
\text { kembali dari } \\
\text { menu } \\
\text { Tentang }\end{array}$ & $\begin{array}{l}\text { Berhasil } \\
\text { kembali dari } \\
\text { menu } \\
\text { Tentang }\end{array}$ & $\begin{array}{l}\text { ( } \sqrt{ }) \text { Diterima } \\
\text { [ ] Ditolak }\end{array}$ \\
\hline
\end{tabular}

Tabel 4 Hasil Pengujian Deteksi Objek Gambar Penanda

\begin{tabular}{|c|c|l|}
\hline Pengujian & Pengamatan & Keterangan \\
\hline \multirow{3}{*}{ Jarak Tangkap } & Jarak $25 C M<$ & Berhasil \\
\cline { 2 - 3 } & Jarak $>25 C M$ & $\begin{array}{l}\text { Tidak } \\
\text { Berhasil }\end{array}$ \\
\hline \multirow{2}{*}{$\begin{array}{c}\text { Sudut } \\
\text { Kemiringan }\end{array}$} & $>15^{0}$ & Berhasil \\
\cline { 2 - 3 } & $15^{0}<$ & $\begin{array}{l}\text { Tidak } \\
\text { Berhasil }\end{array}$ \\
\hline \multirow{3}{*}{ Cahaya } & Terang & Berhasil \\
\cline { 2 - 3 } & Gelap & $\begin{array}{l}\text { Tidak } \\
\text { Berhasil }\end{array}$ \\
\hline \multirow{2}{*}{ Tingkat } & & Berhasil \\
\cline { 2 - 3 } Keakuratan & Rating Bintang $4<$ & $\begin{array}{l}\text { Tidak } \\
\text { Bating Bintang } 4\end{array}$ \\
\hline \multirow{2}{*}{ Respon } & & Tidak \\
& 1 Detik $<$ & Berhasil \\
\cline { 2 - 3 } & & Berhasil \\
\hline
\end{tabular}

\section{Pembahasan}

Penerpan gambar penanda menggunakan tools vuforia yang akan disinkronikasikan pada unity.

Tools vuforia sendiri memiliki konsep penilian kualitas pengenalan gambar penanda, ini dapat membantu peenelitian untuk menentukan gambar penanda yang tepat.

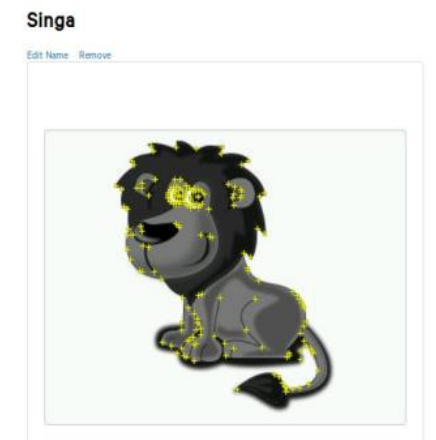

Tipe Single imase
Strous active

STrasta hative

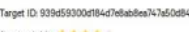

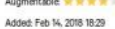

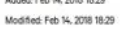

Gambar 8. Penanda Objek Singa

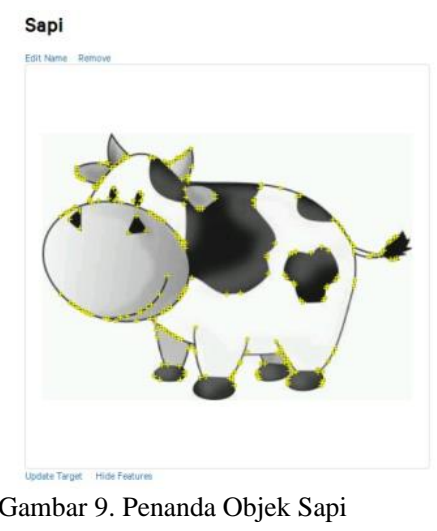

Kambing

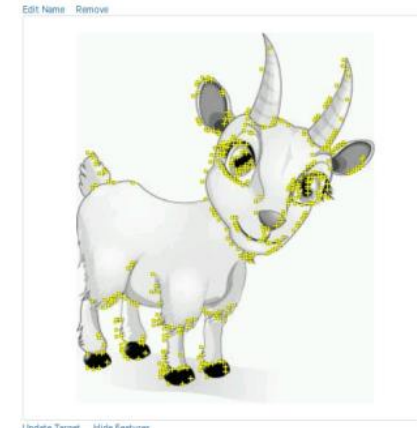

Gambar 10. Penanda Objek Kambing

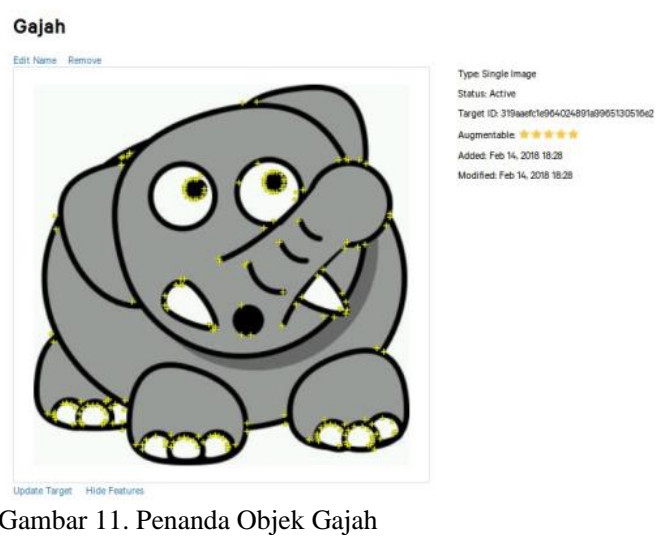



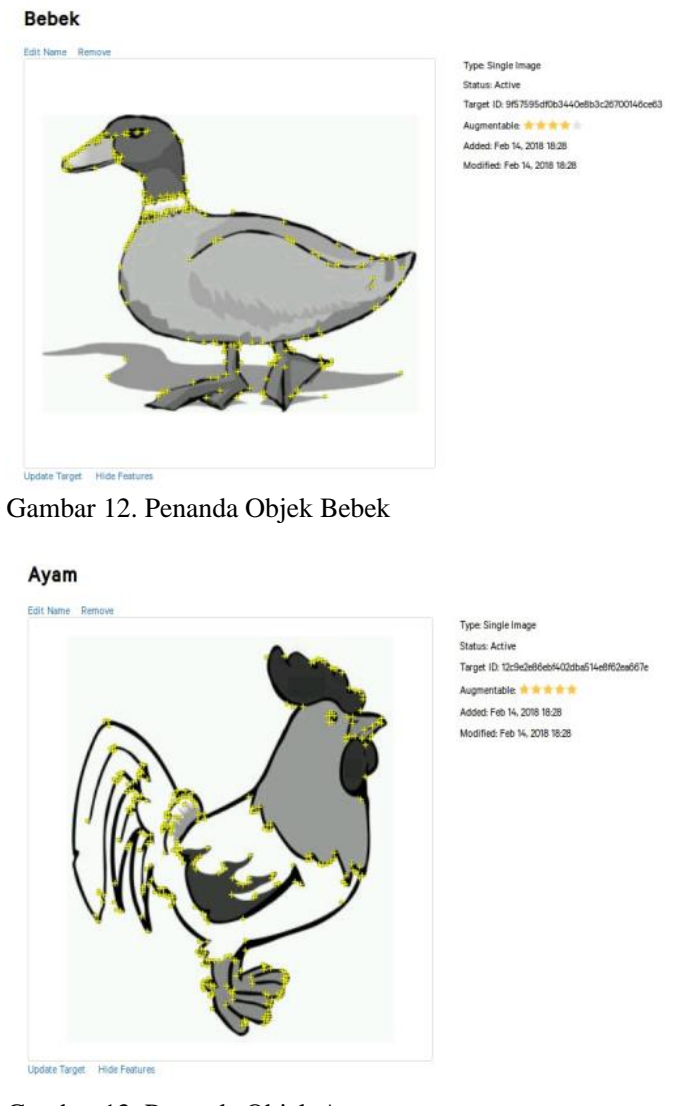

Gambar 13. Penanda Objek Ayam

Tampak pada hasil deteksi gambar penanda menggunakan vuforia diatas, menggunakan deteksi setiap tepi line yang terdapat pada objek penanda yang merupakan penentu dari penilaian objek penanda itu sendiri, semakin rumit tepi line yang dibentuk akan semakin mendapatkan nilai yang baik, nantinya akan berpengaruh pada saat pengenalan dan sudut kamera dalam pengenalan objek 3D yang dihasilkan.

Type: Single Image
Status: Active
Target ID: 12c9e2e86ebf402dba514e8f62ea667e
Augmentable: At th th th
Added: Feb 14, 2018 18:28
Modified: Feb 14, $201818: 28$

Gambar 14. Keterangan Vuforia

Pada gambar diatas disajikan hasil peneliaian objek penanda dengan nilai Augmentable. Serta informasi objek gambar penanda yang digunakan.

\section{Penutup}

\section{Kesimpulan}

Dari hasil analisa, perancangan, pengujian dan implementasi program yang telah dilakukan terhadap Aplikasi Pengenalan Hewan Menggunakan Metode Image Tracking Vuforia dan Teknologi Augmented Reality Berbasis Android, dapat disimpulkan sebagai berikut :

1. Menangkap marker pada jarak $25 \mathrm{CM}<$ untuk menampilkan objek 3D dari marker tersebut dan Sudut kemiringan yang masih terjangkau oleh aplikasi yang dibuat ketika marker telah ditangkap kamera ialah $>15^{\circ}$.

2. Ketika kamera siap mengenali marker dan menampilkan Objek 3D, kamera sistem harus dalam keadaan cahaya terang agar marker dapat dikenali.

3. Dalam mengenali marker tingkat keakuratan tergantung pada rating bintang pada Database Marker, setelah melakukan percobaan rating bintang pada Database Marker minimal 4 bintang.

4. Respon Objek 3D dalam mengenali marker pada sistem yang penulis buat sekitar lebih dari 1 detik setelah kamera siap.

\section{Saran-saran}

Penelitian yang dilakukan tentunya tidak terlepas dari kekurangan dan kelemahan. Oleh karena itu, untuk kebaikan pengembangan sistem lebih lanjut, maka penulis menyarankan beberapa hal di antaranya :

1. Dikarenakan ilmu pengetahuan terus berkembang dan ditemukannya hal-hal baru maka basis pengetahuan dan basis aturan sistem ini perlu di update atau ditambah, sehingga data-data yang ada menjadi lebih lengkap dan kompleks.

2. Penelitian Augmented Reality dengan image target hendaknya juga dapat menampilkan obyek tiga dimensi (3D), animasi dan suara. Untuk Penelitian selanjutnya penulis menyarankan agar membuat aplikasi AR yang lebih interaktif, Objek 3D dapat dibuat bergerak dalam bentuk animasi agar lebih terkesan berinteraksi dengan user dan Aplikasi yang dibuat tidak hanya berjalan pada perangkat android supaya dapat dinikmati banyak pengguna Smartphone seperti ios dan windows phone. 


\section{References}

[1] R. Muhammad, T. Listyorini, and A. Latubessy, "Penerapan teknologi," Pros. SNATIF Ke-1, pp. 267-274, 2014.

[2] M. Billinghurst, A. Clark, and G. Lee, "A survey of augmented reality," Found. Trends Human-Computer Interact., vol. 8, no. 2-3, pp. 73-272, 2014.

[3] N. M. Sudiartini, I. G. M. Darmawiguna, and I. M. G. Sunarya, "Pengembangan Aplikasi Markerless Augmented Reality Balinese Story 'Calon Arang,', J. Pendidik. Teknol. dan Kejuru., vol. 13, no. 2, pp. 233242, 2016.

[4] Y. Rizki, "Markerless Augmented Reality Pada Perangkat Android," J.
Tek. Elektro, vol. 4, no. August, pp. 110, 2012.

[5] A. Nurhayati, I. K. E. Purnama, and A. Zaini, "Analisis Pengujian Perangkat Lunak Augmented Reality," pp. 1-4.

[6] Q. Quraish, R. Kridalukmana, and K. T. Martono, "Buku Pembelajaran Bahasa Inggris dengan Teknologi Augmented Reality Berbasis Android," J. Teknol. dan Sist. Komput., vol. 4, no. 1, p. 102, 2016.

[7] R. F. Raranta, A. Sinsuw, and B. A. Sugiarso, "Pengenalan Teks pada Objek-Objek Wisata di Sulawesi Utara dengan Teknologi Augmented Reality," J. Tek. Inform., vol. 12, no. 1, pp. 2-6, 2017. 